Vol. 4, No. 2, Nopember 2018

p-ISSN: 2442-8884 / e-ISSN: 2541-4542

J-Kesmas

Jurnal Kesehatan Masyarakat

\title{
FAKTOR YANG BERHUBUNGAN DENGAN KELUHAN OTOT DAN TULANG PADA PEKERJA PEMINTALAN TALI DI DUSUN LAMBE DESA KARAMA KECAMATAN TINAMBUNG KABUPATEN POLEWALI MANDAR
}

\author{
Nur Indah Fajriany. BM${ }^{1}$, Maarifah Dahlan ${ }^{2}$ \\ Fakultas Kesehatan Masyarakat, Universitas Al Asyariah Mandar \\ Email : nurindahfajrianybm.indah@yahoo.com
}

\begin{abstract}
ABSTRAK
Industri pemintalan tali di Dusun Lambe Desa Karama Kecamatan Tinambung Kabupaten Polewali Mandar merupakan industri rumah tangga yang dijalankan masyarakat di daerah tersebut sejak tahun 1969 dan bersifat informal. Dalam seharinya satu kelompok menghasilkan 10 rol tali. Dari hasil identifikasi awal dari 15 pekerja yang diwawancarai diketahui 10 pekerja yang mengalami keluhan otot dan tulang. Tujuan penelitian ini untuk mengetahui faktor yang berhubungan dengan keluhan otot dan tulang pada pekerja pemintalan tali di Dusun Lambe Desa Karama Kecamatan Tinambung Kabupaten Polewali Mandar Jenis penelitian ini adalah kuantitatif menggunakan desain cross sectional terhadap 40 pekerja sebagai sampel yang dipilih dengan menggunakan purposive sampling. Analisis data dengan univariat untuk mendeskripsikan karakteristik responden dan bivariat dengan cross tabulasi kemudian diuji menggunakan uji chi square. Hasil penelitian ini menunjukkan bahwa pekerja dengan umur $\geq 35$ tahun lebih banyak mengalami keluhan otot dan tulang yaitu 47,5\% dengan nilai $p$ value $=0,049$, pekerja dengan lama kerja sehari yang tidak memenuhi syarat lebih banyak mengalami keluhan otot dan tulang yaitu 77,5\% dengan nilai $p$ value $=0,003$, dan pekerja dengan sikap tubuh duduk dalam bekerja lebih banyak mengalami keluhan otot dan tulang yaitu $65,0 \%$ dengan nilai $p$ value $=0,149$.
\end{abstract}

Kata kunci : Otot, Tulang, Pekerja Pemintalan Tali, Umur

PENDAHULUAN

International Labour

Organization (ILO) tahun 2013 dalam

program The Prevention of

Occupational Diseases menyebutkan

musculoskeletal disorders termasuk

carpal turnnel syndrome, mewakili 59\%

dari keseluruhan catatan penyakit yang

ditemukan pada tahun 2005 di Eropa.

Laporan Komisi Pengawasan Eropa menghitung kasus Musculoskeletal

disorder menyebabkan 49,9\%

ketidakhadiran kerja lebih dari tiga hari dan $60 \%$ kasus ketidakmampuan permanen dalam bekerja. Sedangkan di Korea, Musculoskeletal disorder mengalami peningkatan yang sangat tinggi dari 1.634 pada tahun 2001 menjadi 5.502 pada tahun 2010 .

Berdasarkan data Departemen

Kesehatan RI (2006), gangguan 
Vol. 4, No. 2, Nopember 2018

p-ISSN: 2442-8884 / e-ISSN: 2541-4542

J-Kesmas

Jurnal Kesehatan Masyarakat

kesehatan yang dialami pekerja 40,5\%

dari pekerjaannya yaitu sebanyak 9482

pekerja di 12 kabupaten/kota di

Indonesia, $16 \%$ diantaranya menderita gangguan musculoskeletal, 8\% penyakit kardiovaskuler, 6\% gangguan syaraf, $3 \%$ gangguan pernafasan dan gangguan THT sebesar $1,5 \%$.

Hasil penelitian yang dilakukan oleh Winda Agustin Rahayu (2012), menunjukkan yaitu ada hubungan antara usia $(p=0.001)$, status gizi $(\mathrm{p}=0.016)$ dan kebiasaan merokok $(\mathrm{p}=0.001) \quad$ dengan keluhan musculoskeletal. Sedangkan masa kerja tidak ada hubungan dengan keluhan musculoskeletal (0.214).

Berdasarkan hasil penelitian yang dilakukan oleh Putu Sukedana (2016) keluhan musculoskeletal pada perakit batu sering dirasakan di bagian pinggang 75\%, persendian siku kanan dan kiri 45,8\%, bahu kiri dan kanan $41,7 \%$, dan pergelangan tangan $37,5 \%$. Pada alat gerak bawah sering mengalami keluhan pada bagian lutut $29,2 \%$, betis $12,5 \%$, dan pergelangan kaki 25\%. Keluhan musculoskeletal pada pemotong batu terjadi pada pinggang, lengan atas, bahu, leher atas dan bawah, siku, dan punggung. Pada alat gerak bawah pemotong batu sering 
Vol. 4, No. 2, Nopember 2018

J-Kesmas

Jurnal Kesehatan Masyarakat

rumus random sampling dan sampel digunakan berjumlah 40 responden.

Dalam penelitian ini terdiri dari variabel independen (umur, lama kerja dan sikap tubuh dalam bekerja) dan variabel dependen (keluhan otot dan tulang). Penelitian ini menggunakan 2 jenis kuesioner yaitu kuesioner data responden untuk mengetahui karakteristik individu berupa jenis kelamin umur, lama kerja, sikap tubuh dalam bekerja, dan kuesioner nordic body map untuk menilai keluhan otot dan tulang pada pekerja pemintalan tali. Analisis data dengan menggunakan uji statistik $\mathrm{X}^{2}$ yaitu chi-square dengan nilai kemaknaan $\alpha=5 \%$.

\section{HASIL PENELITIAN \\ Karakteristik Responden \\ Jenis kelamin}

Tabel 1

Distribusi Responden Menurut Jenis Kelamin Pekerja

\begin{tabular}{ccc}
\hline Jenis kelamin & $\begin{array}{c}\text { Jumlah } \\
\text { (n) }\end{array}$ & (\%) \\
\hline Laki-laki & 8 & 20 \\
Perempuan & 32 & 80 \\
\hline Jumlah & $\mathbf{4 0}$ & $\mathbf{1 0 0}$ \\
\hline
\end{tabular}

Tabel 1 menunjukkan bahwa dari 40 responden, yang berjenis kelamin laki-laki yaitu 8 orang $(20 \%)$ dan yang berjenis kelamin perempuan yaitu 32 orang $(80 \%)$.
p-ISSN: 2442-8884 / e-ISSN: 2541-4542

\section{Pendidikan}

Tabel 2

Distribusi Responden Menurut Tingkat Pendidikan Pekerja

\begin{tabular}{ccc}
\hline Pendidikan & Jumlah (n) & $\mathbf{( \% )}$ \\
\hline SD & 32 & 80 \\
SMP & 4 & 10 \\
SMA & 4 & 10 \\
\hline Jumlah & $\mathbf{4 0}$ & $\mathbf{1 0 0}$ \\
\hline
\end{tabular}

Tabel 2 menunjukkan bahwa dari 40 responden tingkat pendidikan responden yang tertinggi terdapat pada tingkat SD yaitu sebanyak 32 orang (80\%), untuk tingkat pendidikan SMP dan SMA yaitu masing-masing sebanyak 4 orang (10\%).

Umur

Tabel 3

Distribusi Responden Menurut Umur Pekerja

\begin{tabular}{ccc}
\hline Umur (Tahun) & Jumlah (n) & $\mathbf{( \% )}$ \\
\hline$\geq 35$ Tahun & 19 & 47,5 \\
$<35$ Tahun & 21 & 52,5 \\
\hline Jumlah & $\mathbf{4 0}$ & $\mathbf{1 0 0}$ \\
\hline
\end{tabular}

Tabel 3 menunjukkan umur responden yang terbanyak terdapat pada umur $<35$ tahun yaitu sebanyak 21 orang $(52,5 \%)$, sedangkan yang paling sedikit yaitu pada umur $\geq 35$ tahun sebanyak 19 orang $(47,5 \%)$.

\section{Lama kerja}

Tabel 4 
Vol. 4, No. 2, Nopember 2018

p-ISSN: 2442-8884 / e-ISSN: 2541-4542

$\mathrm{J}$-Kesmas

Jurnal Kesehatan Masyarakat

Distribusi Responden Menurut Lama

Kerja Dalam Sehari Pekerja

\begin{tabular}{ccc}
\hline $\begin{array}{c}\text { Lama Kerja dalam } \\
\text { Sehari }\end{array}$ & (n) & (\%) \\
\hline$\leq 8$ jam & 8 & 20 \\
$>8$ jam & 32 & 80 \\
\hline Jumlah & $\mathbf{4 0}$ & $\mathbf{1 0 0}$ \\
\hline
\end{tabular}

Tabel 4 menunjukkan bahwa terdapat 32 orang $(80 \%)$ yang lama kerja dalam sehari tidak yaitu lama bekerja $>8$ jam dan 8 orang (20\%) yang bekerja $\leq 8$ jam

\section{Sikap tubuh dalam bekerja}

Tabel 5

Distribusi Responden Menurut Sikap Tubuh Dalam Bekerja

\begin{tabular}{|c|c|c|}
\hline $\begin{array}{c}\text { Sikap Tubuh } \\
\text { Dalam Bekerja }\end{array}$ & Jumlah (n) & $(\%)$ \\
\hline Berdiri & 12 & $\begin{array}{l}30 \\
\%\end{array}$ \\
\hline Duduk & 28 & $70 \%$ \\
\hline Jumlah & 40 & $\begin{array}{c}100 \\
\%\end{array}$ \\
\hline
\end{tabular}

Tabel 5 menunjukkan bahwa dari 40 responden, yang sikap tubuh berdiri dalam bekerja sebanyak 12 orang (30\%), sedangkan sikap duduk dalam bekerja sebanyak 28 orang $(45 \%)$.

\section{Keluhan otot dan tulang}

Tabel 6

Distribusi Responden Menurut Keluhan Otot dan Tulang

\begin{tabular}{ccc}
\hline $\begin{array}{c}\text { Keluhan Otot dan } \\
\text { Tulang }\end{array}$ & $\begin{array}{c}\text { Jumlah } \\
(\mathbf{n})\end{array}$ & $\begin{array}{c}\text { Persentase } \\
(\%)\end{array}$ \\
\hline Ya & 35 & 87,5 \\
Tidak & 5 & 12,5 \\
\hline Jumlah & $\mathbf{4 0}$ & $\mathbf{1 0 0}$ \\
\hline
\end{tabular}

Tabel 6 menunjukkan pekerja yang mengalami keluhan sebanyak 35 orang $(87,5 \%)$, sedangkan yang tidak mengalami keluhan sebanyak 5 orang $(12,5 \%)$.

Uji Statistik

\section{Hubungan antara umur dengan} keluhan otot dan tulang

Tabel 7

Analisis Hubungan Umur Dengan

Keluhan Otot dan Tulang

\begin{tabular}{|c|c|c|c|c|c|c|c|}
\hline \multirow{3}{*}{ Umur } & \multicolumn{4}{|c|}{$\begin{array}{c}\text { Keluhan Otot dan } \\
\text { Tulang }\end{array}$} & \multirow{2}{*}{\multicolumn{2}{|c|}{ Jumlah }} & \multirow{3}{*}{$\underset{\text { Value }}{P}$} \\
\hline & \multicolumn{2}{|c|}{$\begin{array}{c}\text { Ada } \\
\text { keluhan }\end{array}$} & \multicolumn{2}{|c|}{$\begin{array}{c}\text { Tidak } \\
\text { ada } \\
\text { keluhan }\end{array}$} & & & \\
\hline & $\mathbf{n}$ & $\%$ & $\mathbf{N}$ & $\%$ & $\mathbf{N}$ & $\%$ & \\
\hline $\begin{array}{l}\geq 35 \\
\text { Tahun }\end{array}$ & 19 & $\begin{array}{c}47, \\
5\end{array}$ & 0 & 0 & 19 & 47,5 & \\
\hline $\begin{array}{c}<35 \\
\text { Tahun }\end{array}$ & 16 & $\begin{array}{c}40 \\
0\end{array}$ & 5 & 12,5 & 21 & 52,5 & 0,049 \\
\hline Jumlah & 35 & $\begin{array}{c}87, \\
5\end{array}$ & 5 & 12,5 & 40 & 100 & \\
\hline
\end{tabular}

Berdasarkan tabel 7 mengenai analisis hubungan antara variabel umur dengan keluhan otot dan tulang menggunakan fisher's Exact test, nilai $\mathrm{p}$ value $=0,049$. Karena nilai $\mathrm{p}$ value $<$ 0,05 Ha diterima dan Ho ditolak, sehingga ada hubungan antara umur dengan keluhan otot dan tulang.

Hubungan antara lama kerja dalam sehari dengan keluhan otot dan tulang Tabel 8 
Vol. 4, No. 2, Nopember 2018

p-ISSN: 2442-8884 / e-ISSN: 2541-4542

J-Kesmas

Jurnal Kesehatan Masyarakat

Analisis Hubungan Lama Kerja Dalam

Sehari Dengan Keluhan Otot dan Tulang

\begin{tabular}{|c|c|c|c|c|c|c|c|}
\hline \multirow{3}{*}{$\begin{array}{c}\text { Lama } \\
\text { Kerja } \\
\text { Dalam } \\
\text { Sehari }\end{array}$} & \multicolumn{4}{|c|}{$\begin{array}{c}\text { Keluhan Otot dan } \\
\text { Tulang }\end{array}$} & \multirow{2}{*}{\multicolumn{2}{|c|}{ Jumlah }} & \multirow[b]{2}{*}{ P Value } \\
\hline & \multicolumn{2}{|c|}{$\begin{array}{c}\text { Ada } \\
\text { keluhan }\end{array}$} & \multicolumn{2}{|c|}{$\begin{array}{c}\text { Tidak } \\
\text { ada } \\
\text { keluhan }\end{array}$} & & & \\
\hline & $\mathbf{n}$ & $\%$ & $\mathbf{N}$ & $\%$ & $\mathbf{N}$ & $\%$ & \\
\hline$\leq 8$ jam & 4 & 10,0 & 4 & 10,0 & 8 & 20 & \\
\hline$>8$ jam & 31 & 77,5 & 1 & 2,5 & $\begin{array}{l}3 \\
2\end{array}$ & 80 & 0,003 \\
\hline Jumlah & 35 & 87,5 & 5 & 12,5 & $\begin{array}{l}4 \\
0\end{array}$ & $\begin{array}{c}10 \\
0\end{array}$ & \\
\hline
\end{tabular}

Hasil uji statistik tabel 8 dengan menggunakan fisher's Exact test diperoleh $(p$ value $=0,003)$ karena nilai $\mathrm{p}$ value $<0,05$ maka Ha diterima dan Ho ditolak, sehingga interpretasi dari data diatas menunjukkan ada hubungan antara lama kerja dalam sehari dan keluhan otot dan tulang yang dialami oleh pekerja pemintalan tali

Hubungan antara sikap tubuh dalam bekerja dengan keluhan otot dan tulang

Tabel 9

Analisis Hubungan Sikap Tubuh Dalam Bekerja Dengan Keluhan Otot dan Tulang

\begin{tabular}{|c|c|c|c|c|c|c|c|}
\hline \multirow{3}{*}{$\begin{array}{l}\text { Sikap } \\
\text { tubuh } \\
\text { dalam } \\
\text { bekexia }\end{array}$} & \multicolumn{4}{|c|}{$\begin{array}{l}\text { Keluhan otot dan } \\
\text { tulang }\end{array}$} & \multirow{2}{*}{\multicolumn{2}{|c|}{ Junalah }} & \multirow{2}{*}{ P Vah } \\
\hline & \multicolumn{2}{|c|}{$\begin{array}{c}\text { Ada } \\
\text { keluhan }\end{array}$} & \multicolumn{2}{|c|}{$\begin{array}{c}\text { Tidak ada } \\
\text { keluhan }\end{array}$} & & & \\
\hline & $\mathbf{n}$ & $\%$ & $\mathbf{n}$ & $\%$ & $\mathbf{N}$ & $\%$ & \\
\hline Berdiri & 9 & $\begin{array}{c}22 \\
5\end{array}$ & 3 & 7,5 & 12 & 30 & 0,149 \\
\hline Duduk & $\begin{array}{l}2 \\
6\end{array}$ & $\begin{array}{c}65 \\
0\end{array}$ & 2 & 5,0 & 28 & 70 & \\
\hline Jumlah & $\begin{array}{l}3 \\
5\end{array}$ & $\begin{array}{c}87, \\
5\end{array}$ & 5 & 12,5 & 40 & 100 & \\
\hline
\end{tabular}

Hasil statistik dengan mengunakan fisher's exact test diperoleh $(\mathrm{p}$ value $=0,149)$ karena nilai $\mathrm{p}>0,05$ maka Ha ditolak dan Ho diterima. Interpretasinya bahwa tidak ada hubungan yang bermakna antara sikap tubuh dalam bekerja dengan keluhan otot dan tulang yang dialami pekerja pemintalan tali.

\section{PEMBAHASAN}

Keluhan otot dan tulang adalah sekelompok kondisi patologis yang mempengaruhi fungsi normal dari jaringan halus sistem musculoskeletal yang mencakup sistem syaraf, tendon, dan otot (NIOSH ,1997). Gangguan pada system musculoskeletal tidak pernah terjadi secara langsung, tetapi merupakan kumpulan-kumpulan benturan kecil dan besar yang terakumulasi secara terus menerus dalam waktu relatif lama, dapat dalam hitungan beberapa hari, bulan dan tahun.

Hasil penelitian yang dilakukan pada pekerja pemintalan tali di Dusun Lambe Desa Karama Kecamatan Tinambung Kabupaten Polewali Mandar diperoleh hasil bahwa terdapat 35 orang dari 40 pekerja yang diteliti merasakan keluhan otot dan tulang. 
Vol. 4, No. 2, Nopember 2018

p-ISSN: 2442-8884 / e-ISSN: 2541-4542

J-Kesmas

Jurnal Kesehatan Masyarakat

Berdasarkan hasil Nordic Body

Map (NBM) diketahui terdapat 11

bagian tubuh yang dikeluhakan pekerja yaitu pada bagian bahu kiri, bahu kanan, punggung, lengan atas kanan, pinggang, pantat, lengan bawah kanan, pergelangan tangan kanan, betis kiri, betis kanan dan pergelangan kaki kanan.

Bagian tubuh yang paling banyak dikeluhkan para pekerja yaitu bagian punggung sebanyak 11 orang $(27,5 \%)$.

Hasil penelitian ini sejalan dengan penelitian yang dilakukan oleh Nurliah (2012) pada penelitiannya terkait analisis risiko musculoskeletal diserdos (Musculoskeletal disorder) pada operator forkflit di PT.LLI, didapatkan angka kejadian Musculoskeletal disorder cukup tinggi dari semua operator forkflit yang menjadi responden, $87 \%$ mengalami Musculoskeletal disorder, titik keluhan yang dirasakan antara lain pinggang $(65 \%)$, leher atas (60\%), leher bawah (60\%), punggung (48\%) dan bahu kanan (45\%).

Salah satu faktor yang paling mempengaruhi kejadian keluhan yang dirasakan pekerja pada penelitian ini yaitu faktor umur, seiring bertambahnya umur kebutuhan akan metabolisme tubuh semakin menurun sehingga kemampuan kerja otot pun semakin kecil untuk melakukan pekerjan.

Hasil uji statistik pada pekerja pemintalan tali diperoleh nilai $p$ value $0,049$ ( $p$ value $<0,05)$, sehingga dapat disimpulkan bahwa terdapat hubungan yang bermakna antara umur pekerja dengan keluhan otot dan tulangs.

Hal ini sejalan dengan penelitian yang dilakukan oleh Asni Sang dkk (2013) yang menunjukkan bahwa adanya hubungan yang bermakna antara umur dengan keluhan Musculoskeletal disorder pada pemanen kelapa sawit PT sinergi perkebunan nusantara dengan hasil uji statistik menggunakan fisher exact memperoleh nilai $p=0,004<0,05$.

Hal tersebut juga dibuktikan oleh penelitian Nurhikmah (2011) pada pekerja furnitur, hasil analisis diketahui bahwa terdapat 27 pekerja (81.8\%) berumur $\geq 35$ tahun yang mengalami Musculoskeletal Disorders dan sebanyak 22 pekerja (45.8\%) berumur < 35 tahun yang mengalami Musculoskeletal Disorders. Hasil uji statistik analisis bivariat menunjukkan bahwa ada hubungan bermakna antara umur dengan Musculoskeletal Disorders. hal tersebut terjadi karena semakin lama seeorang bekerja dengan meningkatnya usia maka akan terjadi 
Vol. 4, No. 2, Nopember 2018

p-ISSN: 2442-8884 / e-ISSN: 2541-4542

J-Kesmas

Jurnal Kesehatan Masyarakat

degenerasi yang berupa kerusakan jaringan, penggantian jaringan menjadi jaringan parut, pengurangan cairan sehingga hal tersebut menyebabkan stabilitas pada tulang dan otot menjadi berkurang. Oleh karena itu usia kerja merupakan faktor yang berperan dalam Musculoskeletal Disorders.

Dalam hal ini penelitian ini sesuai dengan teori yang di ungkap Gue et all 1995: Chaffin,1997 dalam AR Fuady (2013) menyatakan bahwa pada umur 35 tahun sebagian pekerja mengalami peristiwa pertama dalam sakit punggung dan tingkat kelelahan akan semakin bertambah sesuai dengan bertambahnya umur. Selain itu, pertambahan umur akan disertai dengan penurunan kapasitas fisik sesorang yang ditandai dengan menurunnya kekuatan otot.

Lama kerja merupakan lamanya seseorang bekerja dalm sehari, lama kerja dapat berpengaruh terhadap timbulnya keluhan otot dan tulang. Keluahn otot dan tulang hampir tidak pernah dirasakan secara langsung, tetapi merupakan hasil akumulasi dari paparan atau hal- hal kecil maupun hal-hal besar yang terjadi secara terus menerus dalam waktu yang lama.

\begin{abstract}
Berdasarkan hasil uji statistik dengan menggunakan uji chi square didapatkan hasil $p$ value 0,003 ( $p$ value $<0,05$ ), sehingga dapat disimpulkan bahwa terdapat hubungan antara lama kerja dalam sehari dengan keluhan otot dan tulang.
\end{abstract}

Hasil penelitian ini sejalan dengan penelitian yang dilakukan oleh AM Watusuke dkk (2016) pada pekerja pencari besi bekas yang menunjukkan bahwa terdapat hubungan antara lam kerja dengan keluhan Musculoskeletal disorder dengan hasil yang didapat nilai $p$ value $=0,002$ atau $p$ value $<0,05$.

Berbeda dengan hasil penelitian yang dilakukan oleh Rende Herlin (2015) pada supir bus jurusan ManadoBitung, dimana hasil uji statistik didaptkan hasil $p=0,049(p<0,05)$, hali ini berarti tidak ada hubungan yang bermakna antara lamanya kerja dengan keluhan musculoskeletal disorders. Hal ini dikarenakan rata-rata waktu kerja supir bus jurusan Manado-Bitung hanya berkisar 3 jam.

Tingginya persentase yang mengalami keluhan otot dan tulang yang bekerja $>8$ jam sehari disebabkan karena mereka mereka melebihi waktu kerja yang dianjurkan yaitu 6-8 jam per hari, waktu kerja bagi seorang pekerja 
Vol. 4, No. 2, Nopember 2018

p-ISSN: 2442-8884 / e-ISSN: 2541-4542

$\mathrm{J}$-Kesmas

Jurnal Kesehatan Masyarakat

sangat menentukan efisiensi dan produktifitas.

Responden yang bekerja $\leq 8$ jam

per hari dan mengalami keluhan hal ini

disebabkan karena pemanfaatan waktu

istirahat yang kurang baik.

Memperpanjang waktu kerja

lebih dari kemampuan tersebut biasanya

disertai dengan penurunan produktivitas

serta kecenderungan untuk timbulnya

hal-hal yang negativ, makin panjang

waktu kerja maskin besar kemungkinan

terjadinya hal-hal yang tidak

diinginkan.

Posisi tubuh dalam bekerja sangat ditentukan oleh jenis pekerjaan yang berbeda-beda terhadap tubuh. Masing-masing posisi kerja mempunyai pengaruh yang berbeda-beda.

Berdasarkan hasil penelitian didaptkan bahwa pekerja dengan sikap tubuh berdiri yaitu 9 orang $(22,5 \%)$ yang mengalami keluhan dan 3 orang (7,5\%) yang tidak mengalami keluhan. Sedangkan dari 28 orang (70\%) sikap tubuh dalam bekerja yaitu duduk terdapat 26 orang $(65,0 \%)$ yang mengalami keluhan dan 2 orang (5,0\%) yang btidak mengalami keluhan otot dan tulang. Uji statistik menunjukkan hasil tidak bermakna atau tidak ada 
Vol. 4, No. 2, Nopember 2018

p-ISSN: 2442-8884 / e-ISSN: 2541-4542

J-Kesmas

Jurnal Kesehatan Masyarakat

KESIMPULAN

Hasil statistik yang menggunakan fisher's exact test diperoleh nilai $(\mathrm{p}$ value $=0,049)$. Karena nilai $\mathrm{p}$ value $<0,05$ Ha diterima dan Ho ditolak. Interpretasinya terdapat hubungan yang bermakna antara umur pekerja dengan keluhan otot dan tulang yang dialami pekerja.

Analisis uji statistik hubungan lama kerja dengan keluhan otot $\mathrm{dn}$ tulang diperoleh $(\mathrm{p}$ value $=0,003)$ karena nilai $\mathrm{p}$ value $<0,05$ maka $\mathrm{Ha}$ diterima dan Ho ditolak, sehingga terdapat hubungan.

Hasil statistik dengan mengunakan fisher's exact test diperoleh $(p$ value $=0,149)$ karena nilai $\mathrm{p}>0,05$ maka Ha ditolak dan Ho diterima. Interpretasinya bahwa tidak ada hubungan yang bermakna antara sikap tubuh dalam bekerja dengan keluhan otot dan tulang yang dialami pekerja pemintalan tali.

SARAN

Kepada pihak perusahaan diharapkan untuk memperhatikan kondisi kerja para pekerja terutama yang terkait dengan lama kerja dan sebaiknya memberlakukan sistem pengorganisasian kerja termasuk diantaranya waktu kerja dan waktu istirahat yang seimbang. Hali ini diperlukan sebagai upaya pencegahan paparan dan yang $>8$ jam sehari sebaiknya memperpanjang dan memanfatkan waktu istirahat untuk melakukan relaksasi otot dan diharapakan mengubah sikap kerjanya menjadi dinamis yang dapat meminimalisir timbulnya keluahan otot dan tulang.

\section{DAFTAR PUSTAKA}

AM Watusuke.2016. Hubungan Antara Lama kerja dan Beban Kerja Dengan Keluhan Musculoskeletal Pada Pekerja Pencari Besi Bekas di Kelurahan Talikuran Utara. Fakultas Kesehatan Masyarakat Universitas Sam Ratulangi.(Online).http://medke sfkm.unsrat.ac.id/wpcontent/upl oads/2016/11/JURNAL.pdf

AR Fuady. 2013. Faktor-Faktor yang Berhubungan Dengan Keluhan Musculoskeletal Disordes (Musculoskeletal disorder) Pada Pengrajin Sepatu di Perkampungan Industri Kecil (PIK) Penggilingan Kecamatan Cakung. (online). http://repository.uinjkt.ac.id.dsp ace/handle/123456789/26496

FY Utari.2015.Hubungan Sikap Kerja Dengan Keluhan Musculoskeletal Pada Penyortir Tembakau di Gudang Sortasi tembakau Kebun Klumpang SUTK PTPN II.(online).http://repository.usu.a c.id/handle/123456789/49578

Internatinal Labour Organization (ILO). 2013 The Preventive Of Occupational 
Vol. 4, No. 2, Nopember 2018

p-ISSN: 2442-8884 / e-ISSN: 2541-4542

$\mathrm{J}$-Kesmas

Jurnal Kesehatan Masyarakat

Disease,(online).Availablefrom:

URL:http://ilo.org/publns/wcms/

208226.pdf.diakses November 2015

Kurniawidjaja L.Meily. 2010. Teori dan Aplikasi Kesehatan Kerja. Jakarta: Penerbit Universitas Indonesia (UI-Press)

Nurhikmah. 2011.Faktor-Faktor yang Berhubungan Dengan

Musculoskeletal Disorders

Pada Pekerja Furnitur di

Kecamatan Benda Kota

Tangerang. Fakultas Kedokteran

dan Ilmu Kesehatan Universitas

Islam Negeri Syarif

Hidayatullah Jakarta

Nurliah. 2012. Analisis Risiko

Musculoskeltal Disorders

(Musculoskeletal disorder) Pada

Operator Forklift di PT LLI.

Fakultas Kesehatan Masyarakat

Universitas Indonesia

Nurhikmah. 2011.Faktor-Faktor yang

Berhubungan Dengan

Musculoskeletal Disorders

Pada Pekerja Furnitur di

Kecamatan Benda Kota

Tangerang. Fakultas Kedokteran

dan Ilmu Kesehatan Universitas

Islam Negeri Syarif

Hidayatullah Jakarta

Putu Sukedana dkk. 2016.

Prevalensi Keluhan

Musculoskeletal dan Keluhan

Kesehatan Lainnya Pada

Pekerja Pura Batu Padas di

Desa Tamblang Dalam Konsep

Health Ergonomic.(online).The

Indonesian Jurnal Of Ergonomic

vol.

2

No.1:JanuariJuni2016.Available

from:URL:http://ojs.unud.ac.id/i ndex.php/jei/article/view/20684.

Rende Herlin.2015. Hubungan Antara

Lama Kerja dan Posisi Kerja

Duduk Dengan Keluhan

Musculoskeletal Pada Supir Bus

Jurusan Manado-Bitung di

Terminal Paal Dua Manado.

Fakultas Kesehatan Masyarakat

Universitas Sam

Ratulangi.(Online).

http://medkesfkm.unsrat.ac.id/in dex.php/27nov2016

Sang Ani.2013. Hubungan Postur Kerja Dengan Keluhan

Musculoskeletal Disorders

(Musculoskeletal disorder) Pada

Pemanen Kelapa Sawit di PT

Sinergi Perkebunan Nusantara.

Fakultas Kesehatan Masayarakat

Universitas

Hasanuddin.(online).

http://repository.unhas.ac.id/bitst ream/handle/123456789/8615/A SNI\%20ANG\%20(K111090291 ).pdf.

WA Rahayu. 2012. Faktor-Faktor Yang Berhubungan Dengan Keluhan Musculoskeletal Pada Pekerja Angkat-Angkut Industri Pemecahan Batu Di Kecamatan Karangnongko Kabupaten Klaten. FKM UNDIP.(online) Jurnal Kesehatan Masyarakat, Vol 1 Nomor 2. Available from: URL:

http://Journals1.undip.ac.id/inde x.php/jkm. 